\title{
Viabilidade do Gesso Acartonado na Construção Civil
}

Ana Flávia Lima Machado ; Bruno Fernandes Finholdt²; Luana da Silva Sousa ${ }^{3}$; Matheus Resende Freitas ${ }^{4}$; Vélcio Carlos Duque Júnior ${ }^{5}$; com orientação de Carolina Oliveira Pinto ${ }^{6}$.

$$
\text { 1,2,3,4,5 Universidade de Uberaba }
$$

anaflavia.lima@hotmail.com¹ e carolina.pinto@uniube.br

\section{1 - Introdução}

A alvenaria de vedação em blocos cerâmicos é muito utilizada no Brasil nos dias atuais, porém, vem perdendo espaço para novas tecnologias, que é o caso da alvenaria em gesso acartonado em paredes internas, devido à rapidez na execução, facilidade de manutenção e reparo, poucos resíduos gerados e diminuição do peso próprio da construção, contribuindo assim na redução de consumo de materiais necessários para parte estrutural da obra reduzindo o uso de armaduras em ate $15 \%$, como destacado por Eder Santin (2000), consequentemente o uso de alvenarias em gesso acartonado é responsável pela redução do preço final da edificação.

Este trabalho acadêmico propôs analisar, a partir dos dados experimentais e fundamentação teórica, as vantagens e desvantagens do uso de alvenarias de vedação em gesso acartonado quando comparada com a alvenaria convencional em blocos cerâmicos, observando a viabilidade, qualidade de acabamentos, isolamento térmico e acústico, resistência ao desgaste e necessidade de mão de obra especializada.

\section{2 - Materiais e métodos}

O trabalho foi desenvolvido por meio de levantamentos na literatura acadêmica relacionados à comparação entre alvearia comum e alvenaria de gesso acartonado publicados entre os anos de 2000 e 2013. Essas publicações foram buscadas em vários bancos de dados como scielo, periódicos capes e backbone, mas principalmente na revista Téchne onde vários artigos acadêmicos serviram como fonte de pesquisa e analises.

O estudo de caso feito pela revista Téchne mostra um comparativo entre dois edifícios de alvenaria comum (um de 12 andares, outro de 20 andares) em relação a dois edifícios em Drywall (também de 12 e 20 andares), como também demostram as vantagens $\mathrm{e}$ desvantagens do Drywall em relação à alvenaria convencional.

\section{3 - Resultados e discussão}

O sistema de Drywall é uma edificação de paredes de gesso mais leves e de menor espessura quando comparado às tradicionais paredes de alvenaria comum. O material apresenta vantagens, como fácil montagem, rapidez e praticidade de instalação. Por outro lado, as paredes de Drywall são exclusivas para ambientes internos, exigem maior atenção para garantir uma boa resistência e necessitam de planejamento especial para o caso de serem utilizadas para pendurar objetos mais pesados.

O uso do método construtivo em Drywall possibilita reduzir custos quando comparado aos métodos construtivos em alvenaria de blocos cerâmicos.

Em estudo publicado na revista Téchne em janeiro de 2000 foi realizado um estudo comparativo entre o uso de gesso acartonado e alvenaria de bloco de concreto no qual se deu da seguinte forma:

Foram utilizadas as mesmas fôrmas, tanto para a alvenaria de concreto, quanto para a alvenaria de gesso acartonado, as especificações dos materiais também foram mantidas iguais, sendo o mesmo concreto, o mesmo sistema de fôrmas e o mesmo tipo de aço. Também foram adotadas cargas acidentais como sendo as mínimas preconizadas pela NBR-6120/80.

Como as mesmas fôrmas foram utilizadas em ambas as situações, a comparação não foi influenciada nem pelo custo nem pela quantidade de mão-de-obra alocada para a execução. Da mesma forma, como foram utilizados os mesmos tipos de materiais, a única diferenciação esteve nas quantidades, porém no caso do concreto, o volume se manteve o mesmo, pois foram

www.uniube.br/entec - UNIUBE Campus Aeroporto - Uberaba/MG 
8을 EnTec - Encontro de Tecnologia da UNIUBE / 28 a 30 de outubro de 2014

utilizados os mesmos materiais e as mesmas fôrmas.

Deste modo, a única alteração de um caso para outro seria a quantidade de aço utilizado nas armaduras, obtendo o seguinte resultado:

Segundo (SANTIN,EDER, 2000, p. 47), uso de gesso acartonado na vedação dos ambientes gera uma menor carga a ser transmitida para as fundações da edificação, podendo chegar a 17 por cento a menos em relação a carga a ser transmitida pela mesma metragem de alvenaria de bloco de concreto, resultando em considerável economia na quantidade de armadura utilizada, sendo possível reduzir em até 15 por cento da quantidade que seria utilizada na alvenaria tradicional, consequentemente reduzir o custo das fundações e armaduras.

\section{4 - Considerações finais}

Como era esperado, observamos que o uso de gesso acartonado no lugar de alvenaria comum traz grandes benefícios. Nos Estados Unidos, cerca de 95\% das residências já fazem uso dos blocos de gesso em paredes, forros ou revestimentos. Dessa forma, a ampliação do seu estudo no Brasil seria de grande valia para que seu uso se torne comum. Uma boa ideia seria usá-lo no interior de casas populares feitas em grande escala ou em apartamentos também populares, já que esses visam principalmente redução de custos, sendo este fator 0 principal benefício gerado pelo uso do gesso acartonado.

\section{5 - Referências}

\section{A economia que vem do}

Drywall. Téchne, São Paulo, nํ4, p.46-48, jan/fev 2000.

BAVA, C. Cenário de Um Novo Tempo.

Arquitetura \& Construção - abr 2004.

BIANCHI, M.L. Na Mira do Construtor.

Téchne, São Paulo, n 51, p.17-19, mar/abr 2001.

CONDEIXA, K.M.S.P. Comparação entre Materiais da Construção Civil Através da
Avaliação do Ciclo de Vida: Sistema Drywall e Alvenaria de Vedação. Rio de Janeiro, Niteroi, 2013. Dissertação (mestrado) - Universidade Federal Fluminense.

Especificação popular. Téchne, São Paulo, no 149, p.32-38, ago 2009. GEROLLA, G. Drywall decorativo. Téchne, São Paulo, no 137, p.40-41, ago 2008.

\section{.Gesso Acartonado: Solução}

Eficiente para Uso Comercial e

Residencial. Qualidade na Construção, São

Paulo, no 26, p. 18-28, abr/mai 2000.

LOTURCO, B. Como fazer reparos em

Drywall? Téchne, São Paulo, no 84, pg.46-48, mar 2004.

MITIDIERI FILHO, C.V. Juntas em Drywall. Téchne, São Paulo, no 100, p.98-103, jul 2005.

NGI-NUCLEO DE GESTÃO E INOVAÇÃO (COOD). Avaliação Pós-Ocupação e Avaliação da Satisfação do Cliente de Sistemas de Drywall - Edificios Residenciais em Porto Alegre. São Paulo, ABRAGESSO/CBCA/CAPA Engenharia/Goldsztein, Abril, 2004.

NOGUEIRA, A.M. DORNELAS, D. JABOURE, D. FLORES, R.L. RODRIGUES, R. J. C. Alvenaria de Vedação Comum x Gesso Acartonado. Minas Gerais, 2004.

Universidade Federal de Minas Gerais

Paredes em chapas de gesso acartonado Knauf. Téchne, São Paulo, no 50, p.72-75, jan/fev 2001. 